\title{
Comparison of weight-adjusted dose versus fixed dose ondansetron in preventing shivering following spinal anaesthesia for caesarean deliveries
}

\author{
Moses Gicheru, Vitalis Mung'ayi, Samina Mir, Jimmie Kabugi
}

Department of Anaesthesia, Aga Khan University, East Africa.

\section{Contact and emails:}

Phone: + 25420366 2158, Email: moses.gicheru@aku.edu; +254 20366 2175, vitalis.mung'ayi@aku.edu; + 25420 366 2158, samina.mir@aku.edu; + 25420366 2158; jimmie.kabugi@aku.edu

\begin{abstract}
Background: Spinal anaesthesia is an effective regional anaesthesia technique, which is preferred in almost $86 \%$ of caesarean sections in the United States and United Kingdom. Eighty percent of caesarean sections done at the Aga Khan University hospital are under spinal anaesthesia. Shivering is a common complication of spinal anaesthesia, it occurs in $40 \%-64 \%$ of patients after neuraxial anaesthesia. Shivering may cause maternal and fetal hypoxemia, maternal discomfort and a problem to the anaesthesiologists when it comes to monitoring the patient during caesarean sections. Ondansetron a 5-HT3 receptor antagonist is effective in treatment and prevention of post-spinal anesthesia shivering. In published studies, use of a fixed dose in patients with different weights, masked the dose effect ondansetron in preventing shivering, such that not adjusting the dose according to the weight of patients' resulted in a higher occurrence of shivering. No study has compared different doses of ondansetron in preventing shivering in parturient women who have had spinal anaesthesia for caesarean section.

Objectives: To determine if a weight-adjusted dose is better than a fixed dose of ondansetron in preventing shivering following spinal anesthesia for caesarean delivery.

Method: This was a randomized, double-blinded controlled trial of 124 women scheduled for elective caesarean surgery. The women were randomized into two equal groups. The intervention group received intravenous ondansetron weight adjusted dosing at $0.1 \mathrm{mg} / \mathrm{kg}$ and the control group received a fixed dose of $4 \mathrm{mg}$ before spinal anesthesia. The occurrence and severity of shivering and other outcomes, such as headache, pruritus were assessed and recorded during the surgery and post-operative period.

Results: A total of 124 patients were included in the study. Social demographic data and baseline vital signs did not differ significantly between the groups. Shivering was observed in 14 patients $(22.6 \%)$ in the control group that received $4 \mathrm{mg}$ ondansetron and 7 patients $(11.3 \%)$ in the intervention group that had $0.1 \mathrm{mg} / \mathrm{kg}$ of ondansetron, but there was no statistical difference between the groups (p- value 0.090). The severity of shivering was greater in the control group compared to intervention group where patients who developed grade two shivering were $8.1 \%$ to $0 \%$ respectively. (P value 0.047 ). There was no difference in the occurrence of pruritus between the two groups. No patient required treatment for very severe shivering.

Conclusion: This study, found that ondansetron weight adjusted dose at $0.1 \mathrm{mg} / \mathrm{kg}$, reduced the severity of shivering when compared to a fixed dose ondansetron at $4 \mathrm{mg}$.

Keywords: Weight-adjusted dose,fixed dose ondansetron, shivering, spinal anaesthesia, caesarean deliveries.

DOI: https://dx.doi.org/10.4314/ahs.v19i3.50

Cite as: Gicheru M, Mung'ayi V, Mir S, Kabugi J. Comparison of weight-adjusted dose versus fixed dose ondansetron in preventing shivering following spinal anaesthesia for caesarean deliveries. Afri Health Sci. 2019;19(3): 2740-2751. https:// dx.doi.org/ 10.4314/ahs.v19i3.50
\end{abstract}

\section{Correspondence author: \\ Vitalis Mung'ayi, \\ Department of Anaesthesia, \\ Aga Khan University, East Africa \\ Phone: +254203662175 \\ Email: vitalis.mung'ayi@aku.edu}

\section{Introduction}

Spinal anaesthesia has found to be an effective regional technique that is preferred in almost $86 \%$ of caesarean sections ${ }^{1}$. Shivering is an involuntary oscillatory skeletal muscle activity, involving one or several muscle groups. It is a reflex response to increase the production of body heat through muscle contraction ${ }^{1-3}$. A published review

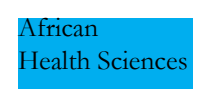

(C) 2019 Gicheru et al. Licensee African Health Sciences. This is an Open Access article distributed under the terms of the Creative commons Attribution License (https://creativecommons.org/licenses/BY/4.0), which permits unrestricted use, distribution, and reproduction in any medium, provided the original work is properly cited.

African Health Sciences Vol 19 Issue 3, September, 2019 
of 21 articles showed an incidence of shivering ranging from $40 \%-64 \%$ with median range of $55 \%$ after neuraxial anaesthesia ${ }^{4}$.

Shivering is a common cause of discomfort to pregnant women during caesarean sections and it has been shown to aggravates wound pain and interfere with wound healing by stretching incisions. Shivering also causes an increase in oxygen consumption and metabolic rate by 40\%-120\%.It promotes catecholamine release, which leads to tachycardia, increases cardiac output and hypertension., ${ }^{5,6}$

Shivering has been correlated with an increase in maternal and fetal hypoxemia, as well as increase in the occurrence of maternal myocardial ischemia. Shivering also increases intraocular and intracranial pressures and it's a troublesome side effect to the anesthesiologist because it interferes with blood pressure monitoring and causes artifacts in ECG and pulse oximetry. ${ }^{1,6,7}$

Vasodilatation caused by the regional technique contributes to cutaneus heat loss by causing the re-distribution of heat from the core thermal compartment to the peripheral thermal compartment, where most of it is lost to the enviroment. Core temperatures drops by a range of $0.5^{\circ} \mathrm{C}$ to $1^{\circ} \mathrm{C}$ after induction of neuraxial anesthesia. This triggers vasoconstriction and shivering above the level of block ${ }^{8,9}$.

Several drugs have been shown to be effective in preventing post anaesthesia shivering in general anaesthesia. But few studies have been done on parturient women undergiong cesarean sections.Tramadol,pethidine,nalbuphine and clonidine have been used in prevention of post anesthesia shivering, but the various side effects of these drugs limit the anesthesiologist from administering these drugs due to harm to the fetus and mother before delivery ${ }^{10,11-17}$.

Ondansetron a 5-HT3 receptor antagonist is used safely in pregnancy for its anti-nausea and anti-emetic effects. No evidence of harm or an increase in adverse fetal outcomes has been reported in pregnant women exposed to ondansetron throughout the course of pregnancy ${ }^{18,19}$. Other/span $>$ uses of ondansetron include prevention and treatment of post-operative nausea and vomiting and treatment of opioid induced pruritus during regional anesthesia. Ondansetron has a high therapeutic index meaning that it has minimal toxic effects when given at high doses as in the case of preventing and treatment of nau- sea and vomiting during chemotherapy. Common adverse effects include headache, constipation, malaise/fatigue. Rapid administration can cause hypotension and tachycardia $^{20}$. Ondansetron has been used to prevent shivering in general and regional anaesthesia. Drugs that lower shivering ${ }_{s}$ can exert their effect by disturbing the central body temperature, so 5-HT antagonist receptors such as ondansetron can be effective in reducing shivering after surgery. The mechanism of action could be related to the inhibition of serotonin reuptake on the pre-optic anterior hypothalamic region. 5-HT3 receptors may also influence both heat production and heat loss pathways ${ }^{21,24}$.

Weight seems to affect the dose dependent effect of ondansetron in preventing shivering. Low dose ondansetron $4 \mathrm{mg}$, was shown to be as effective as $8 \mathrm{mg}$ in patients who weighed $50 \mathrm{~kg}^{10}$

There is a paucity of studies done where ondansetron was used to prevent shivering after spinal anaesthesia for cesarean sections. No study has compared different doses of ondansetron in the prevention of shivering post spinal anaesthesia. This study sought out to investigate whether a weight adjusted dosing of ondansetron, was more effective than a fixed dose in preventing shivering after spinal anesthesia during caesarean sections.

The study was designed to compare the effectiveness of prophylactic ondansetron weight adjusted and fixed dose in the prevention of post anaesthesia shivering following spinal anaesthesia for caesarean delivery. Our study question was: is weight adjusted ondansetron dosing more effective than fixed dosing in preventing post spinal anesthesia shivering in patients undergoing caesarean delivery?

We hypothesized that there is no difference in the occurrence of post-anaesthesia shivering between patients who receive a prophylactic weight-adjusted or fixed dose ondansetron, before spinal anesthesia for caesarean section. Our primary objective was to compare the effectiveness of a weight adjusted dose and a fixed dose ondansetron in preventing shivering, post-spinal anaesthesia for caesarean sections. Our secondary objectives were to compare the grade of shivering between the groups and occurrence of pruritus.

\section{Methods}

The study was performed following approval from the department of anaesthesia and the Ethical and scientif- 
ic review Committee at the Aga Khan University, East Africa. Patients were recruited after having signed an informed consent, which clearly stated that it is a research study being conducted and that their information will be kept confidential. They would receive health care as all other patients who come to theatre, they would not be denied care if they declined to participate in the study. For those who did not understand English, the above information was explained in Swahili. An explanation of the study procedure was given to the patient both verbally and in written form. It was made clear that, there was no direct benefit and no added expenses to the patient arising from participation in the study, but that the results could be used to change local practice in the future.

The patients voluntarily signed the consent form and were recruited in the pre-anesthesia clinic or maternity ward before coming to the operating theatres. The operation did not commence until adequate sensory block was established prior to incision. The patients were free to withdraw from the study at any stage and were to be accorded standard care. This was a prospective double-blinded randomized control trial, where the patient and the anaesthesiologist were blinded as to what dose of ondansetron was administered. The study population included patients admitted for cesarean deliveries at Aga Khan University Hospital, under spinal anaesthesia. The sample population included American Society of Anesthesiologists (ASA) 1 and 2 gravid patients going to theatre for cesarean deliveries under spinal anaesthesia.

All healthy patients over 18 years scheduled for caesarean deliveries under spinal anaesthesia were included in the study. Reasons for exclusion from the study were:

1. Pre-operative use of ondansetron, tramadol, pethidine or clonidine.

2. Allergy or intolerance to ondansetron.

3. Presence of shivering prior to administration of spinal anaesthesia

We based our sample size and power computations on non-inferiority/superiority testing for two sample parallel proportions. For the current study, we assumed a 55\% incidence in proportion of post-anesthesia shivering from the average incidence from studies done in the United States and United Kingdom ${ }^{4}$. Furthermore, for the weight-adjusted dose, we are willing to accept incidence proportion of post-anesthesia shivering that is $18 \%$ lower than for the fixed dose. This translates to a superiority margin of $18 \%$. Based on these conservative parameters, at an alpha of 0.05 , power of 0.80 and sample allocation ratio of 1 , we determined that we required 62 patients in each treatment arm, to make a total of 124 patients. Study participants were recruited from the pre-operative anaesthesia clinic (during the pre-anaesthetic review) and the in-patient maternity ward. Flow diagram of patent participation is shown in figure 1. 


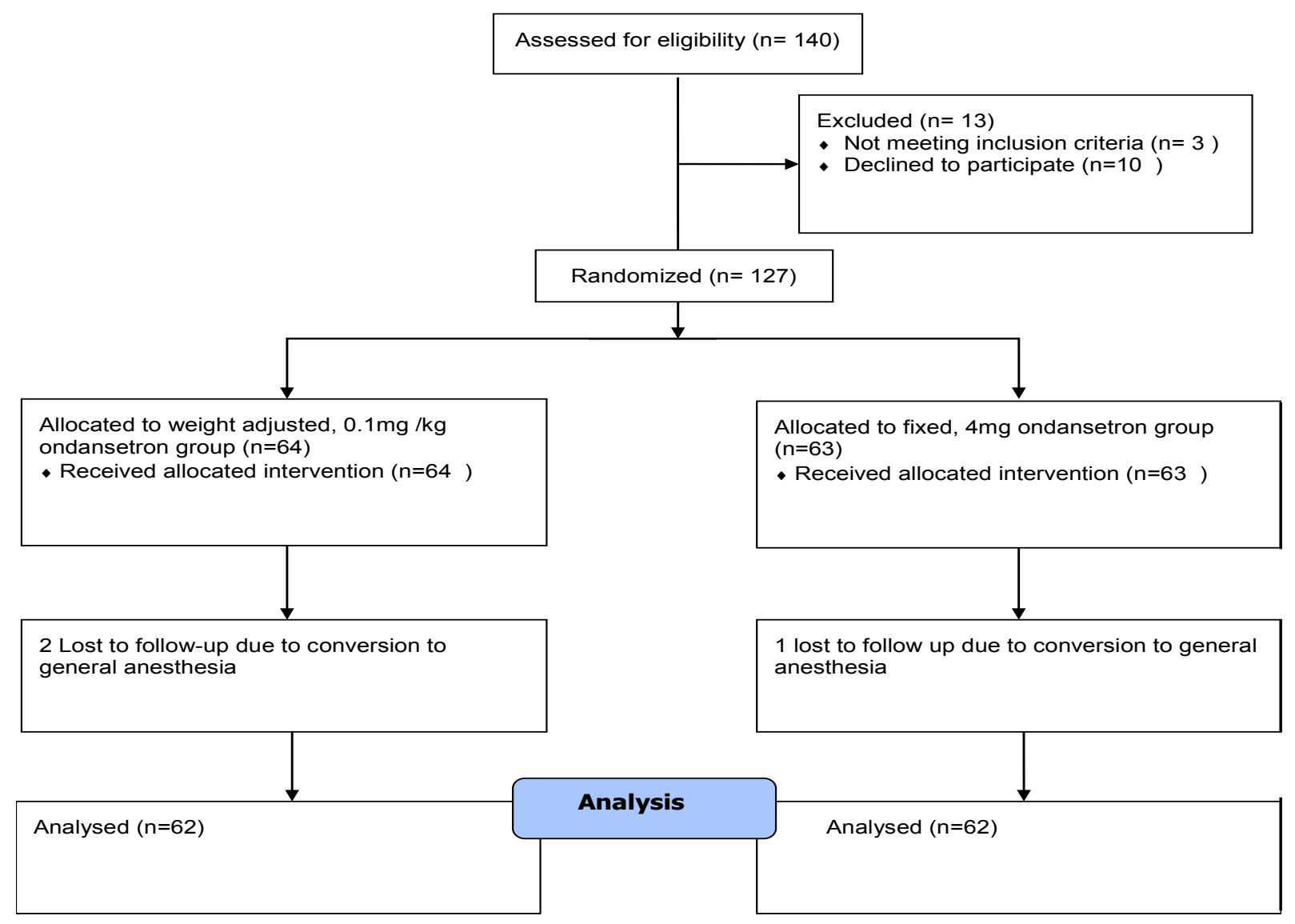

Figure 1: Flow of patient distribution

Simple randomization was done using a computer program; the principal investigator generated a random sequence of numbers. Each of the random numbers were sequentially assigned to either;

Group 1; fixed dose of ondansetron $4 \mathrm{mg}$

Group 2; weight adjusted dose at $0.1 \mathrm{mg} / \mathrm{kg}$

The study drug was prepared by a pharmacist not involved in any other aspect of the study in identical 10 mls syringes labelled study drug. The pharmacist held the code for randomization and group allocation. The drug was then presented to the anaesthesiologist and administered before spinal anaesthesia. The presentation was similar; the only difference was the concentration of the drug in the syringe. Patients scheduled for caesarean section were randomized into two equal groups. The control group received a prophylactic fixed dose $4 \mathrm{mg}$ ondansetron and the intervention group received a prophylactic weight adjusted dose of $0.1 \mathrm{mg} / \mathrm{kg}$ before placement of spinal anesthesia. The anaesthesiologist conducting the procedure received together with the data entry form the study drugs that was prepared in pharmacy. On arrival to the operating theatres, monitoring was carried out with an automated non-invasive blood pressure measurement, electrocardiography and pulse-oximetry for baseline cardiovascular parameters. Core temperature was also taken in the base line parameters and then every $5 \mathrm{~min}$ until end of surgery, using a Temporal Thermometer (TAT-2000c T)

After a local infiltration of $2 \mathrm{ml} 2 \%$ Lidocaine solution, a midline puncture with a 25 French gauge pencil point 
needle was performed at L3/L4 interspace, with the patient in the sitting position. After obtaining free flow of cerebrospinal fluid (CSF), $1.8 \mathrm{mls}$ of bupivacaine and 15ug fentanyl was administered. The patient was then turned supine with a 15 degree left lateral tilt. All patients received crystalloids at room temperature at $20 \mathrm{mls} / \mathrm{kg}$. The sensory block level to both light touch and temperature was checked and modified Bromage motor score recorded. Surgery commenced as soon as the sensory block reached the desired level. Exposed skin was covered with a blanket during preparation and after establishing spinal anaesthesia.

Shivering was graded by the 4-point Bedside Shivering Assessment Scale developed and validated by Badjatia and colleagues ${ }^{28}$ :

$0=$ None,

$1=$ Mild fasciculation in face or neck,

$2=$ Visible tremor in more than one muscle group,

3 =Shivering involving whole body.

This was checked every 5 minutes during surgery shivering above grade 3 or causing distress was to be managed with i.v pethidine $25 \mathrm{mg}$ and any intervention recorded. Intra-operative data was collected by the anesthesiologist administering anesthesia or research assistant (both blinded to patients' group allocation) using the data collection form. Upon collection, data was entered into the statistical software (SPSS. Inc. Chicago, Illinois, USA) on the same day in a coded form and saved, awaiting analysis. The data was verified and In the case of missing data, a follow up to collect the missing data from the pa- tient's medical records was done. In case of conversion to general anesthesia, the patient data was not be analyzed. Standard precautions were taken to respect the privacy of the patients whose data was collected and analyzed in this study. A unique identifier number was used to identify the patient's data. However, in the course of monitoring data quality and adherence to the study protocol only the study supervisors were allowed to refer to the recruited patient's medical records. After analysis, the data was stored in soft copy with the research support unit. Hard copies were also stored in the supervisors' office.

Data analysis was conducted using SPSS (SPSS. Inc. Chicago, Illinois, USA). Descriptive statistics were used to compare patient's characteristics in terms of age, weight, temperature, heart rate and blood pressure. Paired sample T test was used to compare if the two groups were statistically different. Bivariate analysis was used to test for correlation between elective and urgent cesarean sections between intervention and control groups. The data was summarized as means and presented in table form. Twoway ANOVA analysis was used to test associations for shivering, shivering grading, pruritus and sensory level between intervention and control groups. Data was presented as mean +/- standard deviation unless otherwise specified. $\mathrm{P} \leq 0.05$ was considered statistically significant.

\section{Results}

A total of 124 patients were included in the study, 62 patients in each arm. Social demographic data and baseline vital signs did not differ significantly between the groups as shown in table 1.

Table 1: Demographic data

\begin{tabular}{l|c|c|c} 
Parameter & Intervention n=62 & Control n=62 & P value \\
\hline Age & $30.1 \pm 4.6$ & $81.5 \pm 5.2$ & 0.110 \\
\hline Weight & $80.7 \pm 9.1$ & $52.4 \%$ & 0.819 \\
\hline Elective & $41.3 \%$ & & 0.761 \\
\hline Urgent & $57.1 \%$ & $46.0 \%$ & 0.512 \\
\hline
\end{tabular}


We used paired sample $T$ test to test for association between mean age, weight for both intervention and control. In both cases, there was no association. $\mathrm{P}$ values $>$ 0.05. Bivariate analysis used to test for correlation between elective and urgent caesarean sections between intervention and control group. There was no correlation. $\mathrm{P}$ values $>0.05$. The pre-operative baseline parameters and block heights were similar in both groups. This is shown in table 2 and 3 respectively. The temperature before spinal anesthesia was comparable between the two groups. There was gradual reduction in temperature in the two groups that was maximum at $30 \mathrm{~min}$.The intervention group had a higher drop in core temperatures. This is illustrated in figure 2 below.

Table 2: Pre-operative baseline signs

\begin{tabular}{|l|c|c|c|}
\hline Parameter & $\begin{array}{l}\text { Intervention n } \\
=62\end{array}$ & $91.61 \pm 12.2$ & 0.811 \\
\hline Pulse & $91 \pm 13.0$ & $118.7 \pm 14.0$ & 0.980 \\
\hline Systolic & $118.6 \pm 12.6$ & & Pontrol n=62 \\
\hline Diastolic & $73.2 \pm 10.6$ & $74.0 \pm 12.3$ & 0.749 \\
\hline MAP & $82.8 \pm 18.2$ & $87.7 \pm 14.6$ & 0.093 \\
\hline Baseline & $37.8 \pm .54$ & $37.0+0.58$ & 0.070 \\
\hline Temperature & & & \\
\hline
\end{tabular}

Table 3: Block height

\begin{tabular}{|l|l|l|l|}
\hline Block level & Intervention $n=62$ & Control $n=62$ & P value \\
\hline T4 & $46.8 \%(29)$ & $62.9 \%(39)$ & 0.301 \\
\hline T5 & $33.9 \%(21)$ & $19.4 \%(12)$ & \\
\hline T6 & $19.4 \%(12)$ & $16.1 \%(10)$ & \\
\hline T7 & $0 \%(0)$ & $1.6(1)$ & \\
\hline
\end{tabular}




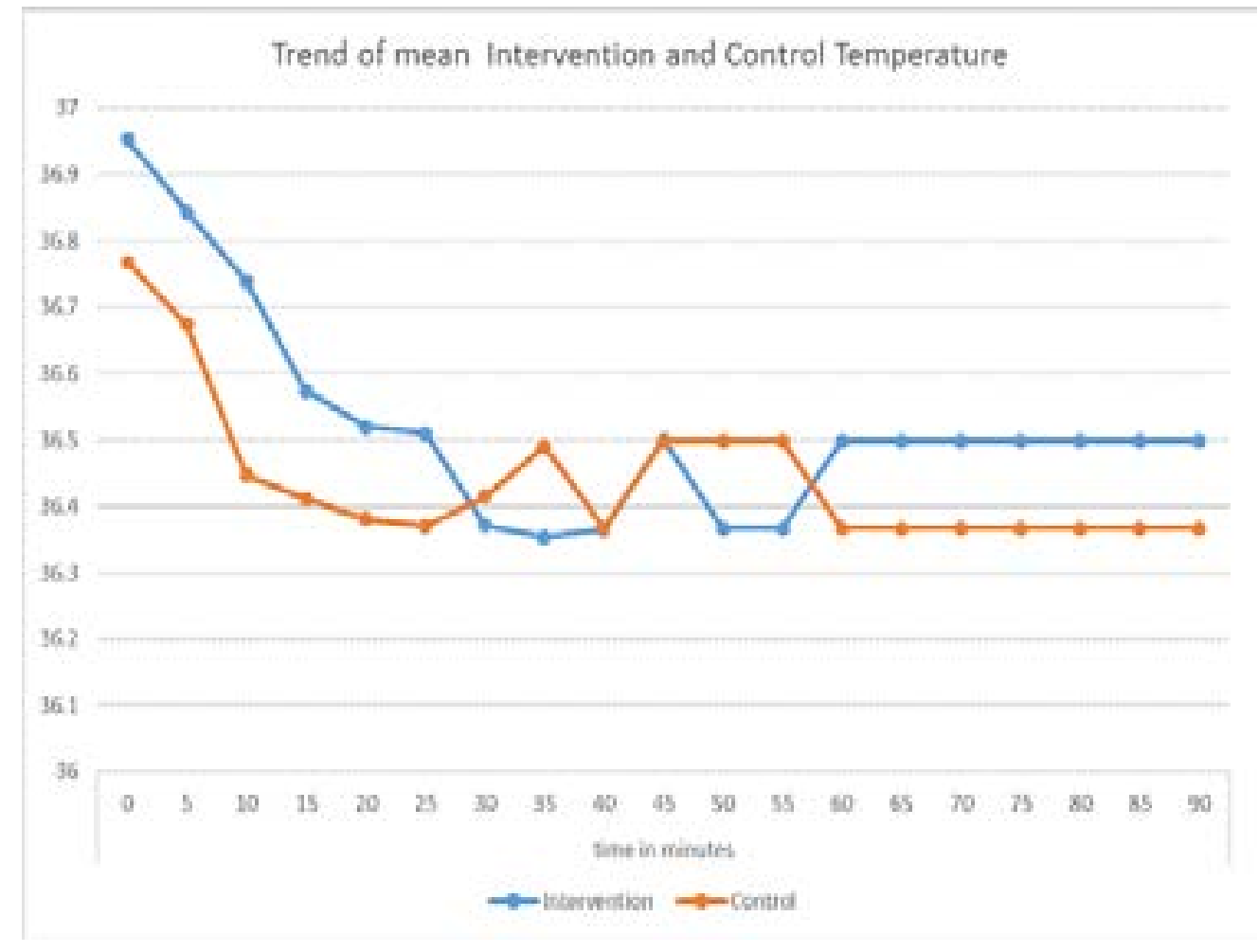

Figure 2: Temperature Trend

Shivering was observed in 14 patients (22.6\%) in the control group that received $4 \mathrm{mg}$ ondansetron and 7 patients $(11.3 \%)$ in the intervention group that had $0.1 \mathrm{mg} / \mathrm{kg}$ of ondansetron, but there was no statistical difference between the groups ( $\mathrm{p}$ - value 0.090). This is shown in table 4 and illustrated in figure 3 .

Table 4: Incidence of shivering

\begin{tabular}{|l|l|l|l|}
\hline Shivering & Intervention $n=62$ & Control $n=62$ & P value \\
\hline Occurrence & $11.3 \%(7)$ & $22.6 \%(14)$ & 0.090 \\
\hline No occurrence & $88.7(52)$ & $77.4(48)$ & \\
\hline
\end{tabular}




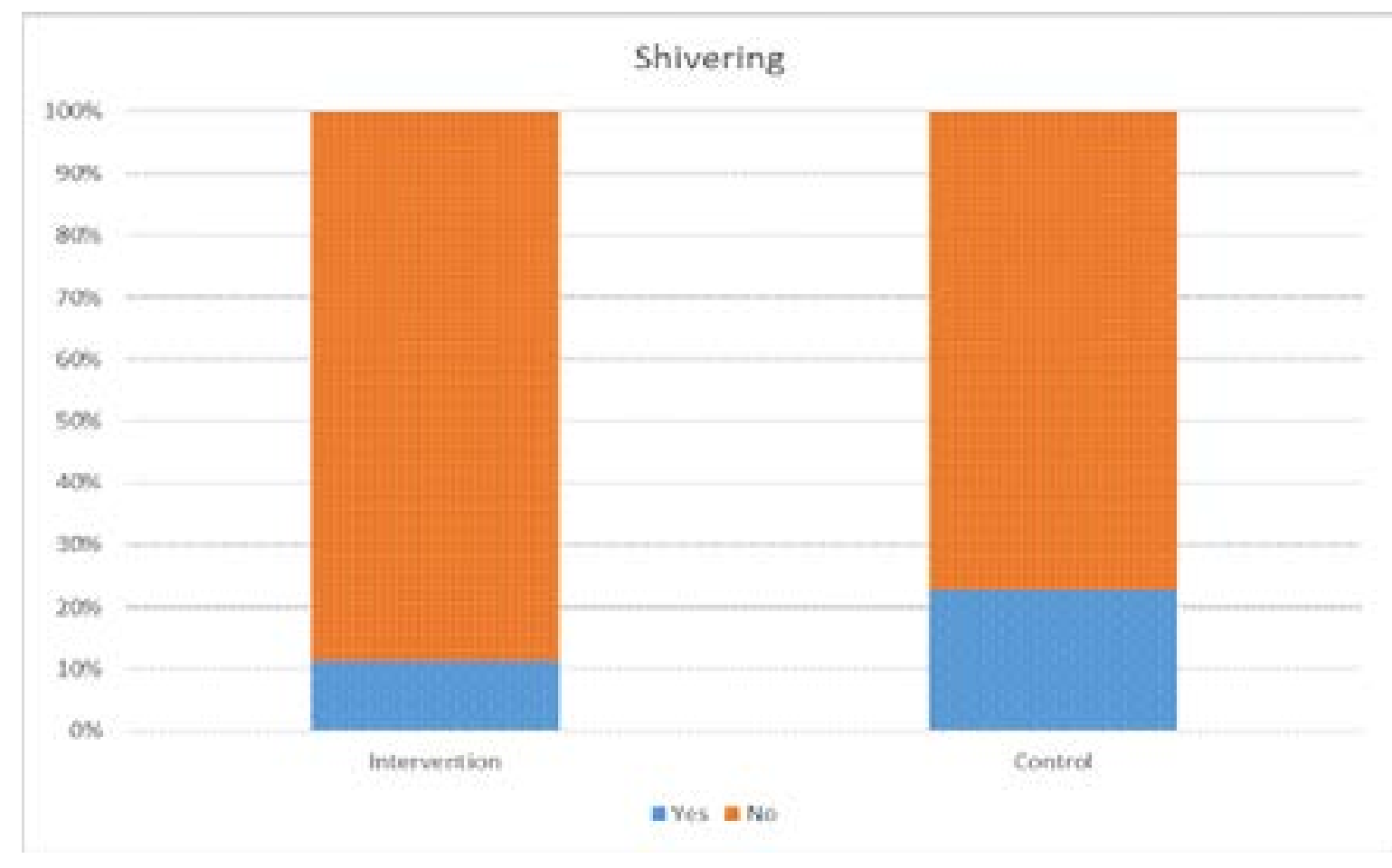

Figure 3: Occurrence of shivering

The intervention group had significantly less patients to control group, $0 \%$ to $8.1 \%$ respectively. (P value 0.047 ) who developed more than grade one shivering compared as illustrated in table 5 and figure 4.

Table 5: Severity of shivering

\begin{tabular}{|l|l|l|l|}
\hline Severity of shivering & intervention & control & P value \\
\hline Grade 1 & $11.3 \%(7)$ & $12.9 \%(8)$ & \\
\hline Grade 2 & $0 \%(0)$ & $8.1 \%(5)$ & 0.047 \\
\hline
\end{tabular}




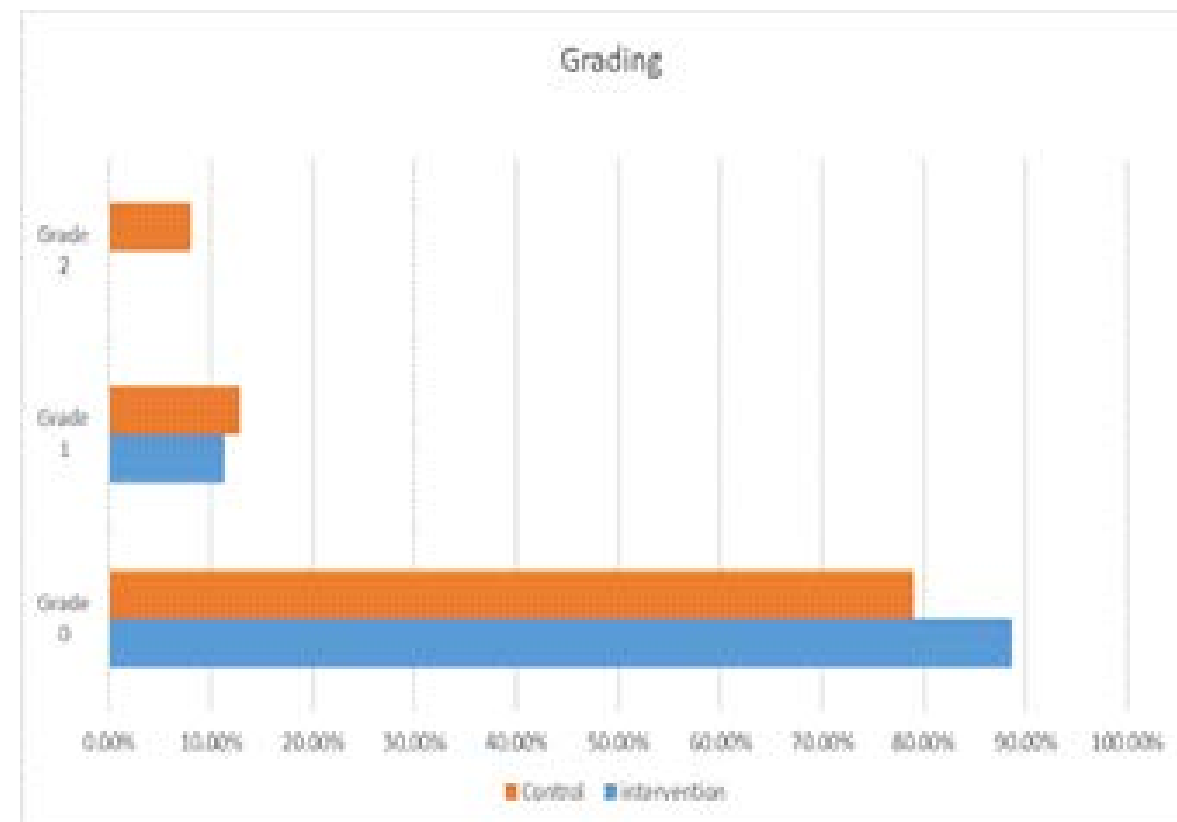

Figure 4: Grading of severity of shivering

Occurrence of pruritus was less in the intervention group patients $(11.3 \%)$ respectively. However, the occurrence compared to the control group at 4 patients $(6.5 \%)$ to 7 was comparable statistically. (P-value 0.398$)$ as illustrated in table 6 and figure 5.

Table 6: Incidence of pruritus

\begin{tabular}{|l|l|l|l|}
\hline Pruritus & Intervention & Control & P value \\
\hline No Pruritus & $93.5 \%(58)$ & $88.7 \%(55)$ & 0.398 \\
\hline Presence of pruritus & $6.5 \%(4)$ & $11.3 \%(7)$ & \\
\hline
\end{tabular}




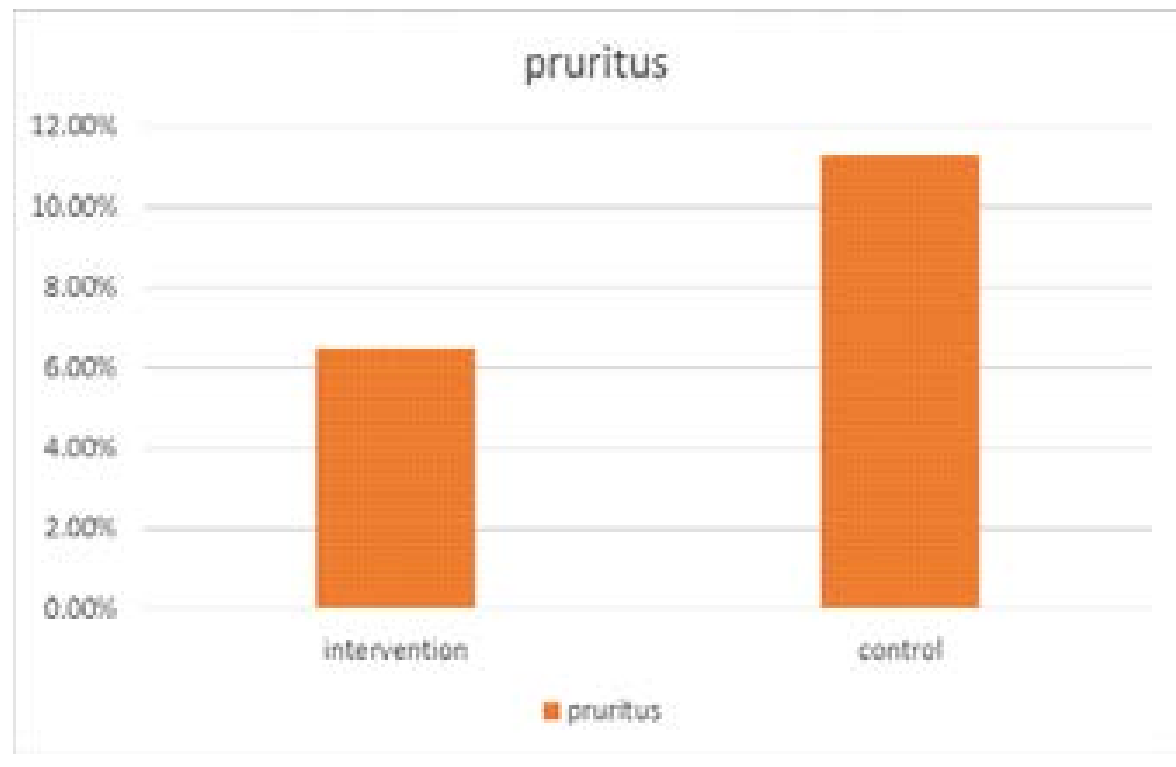

Figure 5: Occurrence of pruritus

\section{Discussion}

The major findings in this study was that ondansetron at $0.1 \mathrm{mg} / \mathrm{kg}$, reduced the occurrence of shivering compared to a fixed dose $4 \mathrm{mg}$,after spinal anaesthesia but this was not statistically significant. The severity of shivering when $0.1 \mathrm{mg} / \mathrm{kg}$ was administered was less compared to $4 \mathrm{mg}$ group, and this was statistically significant. Ondansetron has been used in previous studies in doses ranging from $4 \mathrm{mg}$ to $8 \mathrm{mg}$, to prevent shivering occurring during regional and general anesthesia, the average dose in our intervention group was $8.1 \mathrm{mg}^{17,21-24}$. The rationale for using a weight based dosing was that in pregnant women there are physiological changes that include; increase in total body water and body fat composition that lead to an increase the volume of distribution of the drug. Reduction in albumin concentration may reduce the drug binding and increase total free drug concentration. Increase in renal blood flow and glomerular filtration may lead to a rapid drug excretion. These changes may lead to drug under dosing or over dosing. A weight-adjusted dose at $0.1 \mathrm{mg} / \mathrm{kg}$ was seen to be effective in treatment of post-operative shivering.

From a meta-analysis by $\mathrm{K} \mathrm{He}$ et al both $4 \mathrm{mg}$ and $8 \mathrm{mg}$ ondansetron were found to reduce the occurrence of shivering significantly, they evaluated a total of 905 patients going for surgery from 8 randomized control trials ${ }^{25}$. Ejiro et al carried out a similar study and compared low dose ondansetron at $4 \mathrm{mg}$ with tramadol and placebo in preventing shivering post spinal anesthesia for cesarean sections. The incidence of shivering was $20 \%$, in the ondansetron group compared to $16.7 \%$ and $53 \%$ in the tramadol and placebo group respectively. The conclusion was that at $4 \mathrm{mg}$ ondansetron was comparable to tramadol in preventing shivering. The results tallied with what was found in the control group arm of our study where $4 \mathrm{mg}$ was administered. The occurrence of shivering was at $22.6 \%$ in our study ${ }^{17}$.

Powel compared a low dose ondansetron at $4 \mathrm{mg}$ and a higher dose of $8 \mathrm{mg}$ to reduce the occurrence of shivering during surgery under general anesthesia. Results showed an occurrence of shivering of $33 \%$ and $15 \%$ respectively. This was an 18\% difference in the occurrence of shivering between the groups. This was comparable to our study, where the occurrence of shivering was $11.3 \%$ in the weight adjusted dose of $0.1 \mathrm{mg} / \mathrm{kg}$ compared to $22.6 \%$ in the fixed dose $4 \mathrm{mg}$. The difference was $11.3 \%$. In both studies, the difference in the results in the two groups were not statistically significant ${ }^{21}$.

Browning et al compared 8mg ondansetron to placebo in preventing shivering after combined spinal epidural anesthesia. They found an occurrence of $47 \%$ in placebo group compared to $42 \%$ in the ondansetron group. Compared to our study where $0.1 \mathrm{mg} / \mathrm{kg}$ ondansetron was ad- 
ministered the occurrence was less at $11.3 \%$. Browning concluded that ondansetron does not reduce the occurrence of shivering compared to placebo ${ }^{23}$. Browning also did not find a difference in the severity of shivering between placebo and $8 \mathrm{mg}$ of ondansetron. This differed from our study where $0.1 \mathrm{mg} / \mathrm{kg}$ ondansetron reduced the severity of shivering significantly compared to a fixed dose at $4 \mathrm{mg}$. Although there was no statistical difference in the severity of shivering between $8 \mathrm{mg}$ ondansetron and placebo, the number of patients who required clonidine for treatment of severe shivering were more on the placebo group compared to $8 \mathrm{mg}$ group. Three patients in the placebo group compared to none in the ondansetron group. This study differed from our study in the grading of shivering where grade one was termed as the presence of piloerection and peripheral vasocnstriction without muscle activity. This is a normal physiological response and does not necessarily reflect a clinically important shivering response. This may have led to an increased observation of severe shivering and the lack of difference between placebo and $8 \mathrm{mg}$ ondansetron ${ }^{23}$.

The current study found a reduction in the incidence of shivering in the weight-adjusted dose compared to the low dose $4 \mathrm{mg}$ ondansetron, $22.6 \%$ compared to $11.6 \%$ respectively. However, this was not statistically significant. The reason for this could be the use of intrathecal fentan$\mathrm{yl}$ in our study, as it is the standard of care in the hospital. Intrathecal fentanyl is shown to reduce the occurrence of shivering by up to $50 \%$ in parturient women going for cesarean section under spinal and epidural anesthesia ${ }^{26}$.The occurrence of pruritus between the higher weight adjusted dose and fixed lower dose was shown to be similar statistically, however the higher dose had fewer patients who developed pruritus. 6.5\% compared to $11.5 \%$ respectively with a $\mathrm{p}$ value of 0.398 . From a systematic review by Bonnet et al both low and high dose ondansetron were effective in preventing shivering due to intrathecal opioids $^{27}$.

\section{Strengths of the study}

After a rigorous literature review, it appears that this is the first prospective randomized controlled study that has compared different doses of ondansetron in preventing shivering in parturient women who have had spinal anaesthesia for caesarean section. Therefore, this study will add to the body of literature and knowledge on prevention of shivering following spinal anaesthesia given for caesarean section and probably form a basis for many other studies in the future.

\section{Limitations of the study}

We did not factor the effects of anxiety on shivering which could have a similar presentation. The study was conducted at a single center and involved a relatively small number of patients; this may affect the generalizability of the results of this study. The calculation of the power of the current study was based on small and not large randomized clinical trials due to paucity of published studies on use of ondansetron in parturient women going for caesarean sections.

\section{Conclusion}

On the basis of the results of this study, ondansetron weight adjusted dose at $0.1 \mathrm{mg} / \mathrm{kg}$, reduced the severity of shivering when compared to a fixed dose ondansetron at $4 \mathrm{mg}$ in patients undergoing spinal anaesthesia for caesarean delivery.

\section{Conflict of interest}

None declared.

\section{References}

1. Alfonsi P. Post-anaesthetic shivering. Epidemiology, pathophysiology and approaches to prevention and management. Minerva Anestesiol. 2003 May;69(5):438-42.

2. Sessler DI. Thermoregulatory defense mechanisms. Crit Care Med. 2009 Jul;37(7):S203-10.

3. Bozgeyik S Mizrak A, Kilic E, Yendi F, Uqur BK. The effects of preemptive tramadol and dexmedetomidine on shivering during arthroscopy. Saudi J Anaesth. 2014 Apr;8(2):238-43.

4. Crowley LJ, Buggy DJ. Shivering and Neuraxial Anesthesia. Reg Anesth Pain Med. 2008 May-Jun;33(3):241-52.

5. De Figueiredo Locks G. Incidence of Shivering after Cesarean Section under Spinal Anesthesia with or without Intrathecal Sufentanil: A Randomized Study. Rev Bras Anestesiol. 2012 Sept-Oct;62(5):676-84.

6. Abdelrahman RS. Prevention of shivering during regional anaesthesia: Comparison of Midazolam, Midazolam plus ketamine,Tramadol, and Tramadol plus Ketamine. Life Sci J. 2012;9(2):132-9.

7. Bhattacharya PK, Bhattacharya L, Jain RK, Agarwal. Post Anaesthesia Shivering ( PAS ): A Review. Indian J Anaesth. 2003;47(2):88-93.

8. Buggy DJ, Crossley AW. Thermoregulation, mild 
perioperative hypothermia and postanaesthetic shivering. BrJ Anaesth. 2000 May ;84(5):615-28.

9. Evenson KR, Mottola MF, Owe KM, Rousham EK, Brown WJ. (2014) Summary of international guidelines for physical activity after pregnancy. Obstet Gynecol Surv 2014 Jul ;69(7):407-14.

10. Tie HT, Su GZ, He K, Liang SR, Yuan HW, Mou $\mathrm{JH}$. Efficacy and safety of ondansetron in preventing postanesthesia shivering: a meta-analysis of randomized controlled trials. BMC Anesthesiol. 2014 Mar 3;14:12.

11. Tsai YC, Chu KS. A comparison of tramadol, amitriptyline, and meperidine for postepidural anesthetic shivering in parturients. Anesth Analg. 2001 Nov;93(5):1288-92. 12. Javaherforoosh F, Akhondzadeh R, Aein KB, Olapour A, Samimi M. Effects of tramadol on shivering post spinal anesthesia in elective cesarean section. Pak J Med Sci. 2009;25(1):12-17.

13. Kyokong O, Tamdee D, Charuluxananan S. Comparison of the efficacy of nalbuphine, tramadol, ondansetron and placebo in the treatment of postanesthetic shivering after spinal anesthesia for cesarean delivery. Asian Biomedicine. 2007;8:1(2).

14. Chan AM, Ng KF, Tong EW, Jan GS. Control of shivering under regional anesthesia in obstetric patients with tramadol. Can J Anaesth. 1999 Mar;46(3):253-8.

15. Casey WF, Smith CE, Katz JM, O’Loughlin K, Weeks SK. Intravenous meperidine for control of shivering during Caesarean section under epidural anaesthesia. Can J Anaesth. 1988 Mar;35(2):128-33.

16. Hidayah MN, Liu CY, Joanna OS. Ketamine and tramadol for the prevention of shivering during spinal anaesthesia. Clin Ter. 2014;165(4):193-8.

17. Ejiro BA, Edomwonyi NP, Imarengiaye CO. Ondansetron versus Tramadol in the Prevention of Postanaesthesia Shivering following Caesarean Section Under Spinal Anaesthesia. African Journal of Anaesthesia and Intensive Care. 2014;6: 14(1).

18. Ondansetron looks safe in pregnancy, so far. BMJ. 2013;347:f1387.
19. Pasternak B, Svanström H, Hviid A. Ondansetron in pregnancy and risk of adverse fetal outcomes. $N$ Engl J Med. 2013 Feb;368:814-23.

20. Ye JH, Ponnudurai R, Schaefer R. Ondansetron: a selective 5-HT(3) receptor antagonist and its applications in CNS-related disorders. CNS Drug Rev. 2001;7(2):199-213. 21. Powell RM, Buggy DJ. Ondansetron given before induction of anesthesia reduces shivering after general anesthesia. Anesth Analg. 2000 Jun;90(6):1423-7.

22. Shakya S, Chaturvedi A, Sah BP. Prophylactic low dose ketamine and ondansetron for prevention of shivering during spinal anaesthesia. J Anaesthesiol Clin Pharmacol. 2010 Oct;26(4):465-9.

23. Browning RM, Fellingham WH, O'Loughlin EJ, Brown NA, Paech MJ. Prophylactic ondansetron does not prevent shivering or decrease shivering severity during cesarean delivery under combined spinal epidural anesthesia: a randomized trial. Reg Anesth Pain Med. 2013 Jan-Feb;38(1):39-43.

24. Kelsaka E, Baris S, Karakaya D, Sarihasan B. Comparison of ondansetron and meperidine for prevention of shivering in patients undergoing spinal anesthesia. Reg Anesth Pain Med. 2006 Jan-Feb;31(1):40-5.

25. He K, Zhao H, Zhou HC. Efficiency and safety of ondansetron in preventing postanaesthesia shivering. Ann R Coll Surg Engl [Internet]. 2016 Jul;98(6) 358-66.

26. Sadegh A, Tazeh-kand NF, Eslami B. Intrathecal fentanyl for prevention of shivering in spinal anesthesia in cesarean section. Med J Islam Repub Iran. 2012 May;26(2):85-9.

27. Bonnet MP, Marret E, Josserand J, Mercier FJ. Effect of prophylactic 5-HT3 receptor antagonists on pruritus induced by neuraxial opioids: A quantitative systematic review. Br J Anaesth. 2008 Sep;101(3):311-9.

28. Badjatia N1, Strongilis E, Gordon E, Prescutti M, Fernandez L, Fernandez A, Buitrago M, Schmidt JM, Ostapkovich ND, Mayer SA. Metabolic impact of shivering during therapeutic temperature modulation: the Bedside Shivering Assessment Scale. Stroke. 2008 Dec;39(12):3242-7 